\title{
Perceptions of Mental Health and Help-Seeking Behavior in an Urban Community in Vietnam: An Explorative Study
}

\author{
Lia van der Ham • Pamela Wright . \\ Thang Vo Van · Vuong D. K. Doan • \\ Jacqueline E. W. Broerse
}

Received: 26 February 2009/ Accepted: 28 February 2011/Published online: 16 March 2011

(C) The Author(s) 2011. This article is published with open access at Springerlink.com

\begin{abstract}
This explorative study assesses perceptions of mental health and help-seeking behavior among adults in Vietnam. Methods included questionnaires (200) and focus group discussions (eight). Respondents were often unable to name specific mental illnesses. Frequently mentioned symptoms of mental illness were talking nonsense, talking/ laughing alone and wandering. Pressure/stress and studying/thinking too much were often identified causes. Most respondents showed a preference for medical treatment options, often in combination with family care. The results show that perceptions of mental health and help-seeking behaviour are influenced by a lack of knowledge and a mix of traditional and modern views.
\end{abstract}

Keywords Mental health - Mental illness - Perceptions · Help-seeking behavior

L. van der Ham $(\varangle) \cdot$ J. E. W. Broerse

Athena Institute, VU University Amsterdam, De Boelelaan 1085, 1081 HV Amsterdam, The Netherlands

e-mail: lia.van.der.ham@falw.vu.nl

J. E. W. Broerse

e-mail: jacqueline.broerse@falw.vu.nl

P. Wright

Medical Committee Netherlands-Vietnam, Weteringschans 32, 1017 SH Amsterdam, The Netherlands

e-mail: pamela.wright@mcnv.nl

T. V. Van · V. D. K. Doan

Faculty of Public Health, Hue College of Medicine

and Pharmacy, 06 Ngo Quyen Street, Hue city,

Thua Thien Hue province, Vietnam

e-mail: vovanthang147@hotmail.com

V. D. K. Doan

e-mail: doankhanh72@yahoo.com

\section{Introduction}

Mental disorders may affect one out of four people during their lives (Kessler et al. 1994; Hwu et al. 2007). These disorders include unipolar depressive disorders, bipolar affective disorders, schizophrenia, alcohol and drug use disorders, obsessive and compulsive disorders and panic disorders (World Health Organization 2001). They change the functioning and thinking processes of the individual and often reduce his social role and productivity in the community. Because mental illnesses are disabling and may last for many years, they also place a huge burden on the emotional and socio-economic capacity of the family members who care for the patient (World Health Organization 2001). The global burden of disease of mental illness is high and is expected to rise (Mathers and Loncar 2006). At present, anxiety and mood disorders are the most common mental problems worldwide (WHO World Mental Health Consortium 2004) and it has been predicted that unipolar depressive disorders will be the second leading cause of burden of disease in 2030 (Mathers and Loncar 2006). Most people suffering from mental health problems live in developing countries, where they often do not receive the treatment they need even though it may be available and generally inexpensive (Patel et al. 2006). In these countries, mental illness is more often associated with stigma than in more developed countries (World Health Organization 2001). Up to today, mental health remains a neglected topic. Interventions aimed at decreasing the burden of mental disease are limited, especially in low and middle-income countries (Jacob et al. 2007).

As a consequence of rapid demographic and socioeconomic changes, Vietnam is in an epidemiological transition. There is a double burden, with decreasing but still high rates of infectious diseases along with increasing rates 
of non-communicable diseases including mental disorders (Giang 2006). The burden of mental health problems is high and appears to be rising, but the health system still pays little attention to mental health. Access to mental health care is limited and few health policies address mental health (Harpham and Tuan 2006). For a long time the national plan of action focused only on the treatment of schizophrenia and epilepsy in hospitals. Although epilepsy is a neurological disorder, it is often (as is the case in Vietnam) treated in mental health care settings by psychiatrists because people with epilepsy often have considerable psychiatric comorbidity and share many of the same problems with the mentally ill regarding training, planning of services and treatment (Giel and Harding 1976; Mbuba and Newton 2009). Since 2004, the national plan proposed to incorporate screening for mental illness among women and children to implement early detection and treatment.

Research on mental health in Vietnam is limited and few studies have been published about the prevalence of mental disorders. Fisher et al. (2004) found that 33\% of the women attending general health clinics in Ho Chi Minh City were depressed after giving birth and $19 \%$ of them explicitly acknowledged suicidal thoughts. Giang (2006) found a prevalence of $5.4 \%$ of mental distress in a rural area in Vietnam. Only $42 \%$ of those people, however, received treatment for their problems and only 5\% sought treatment at official mental health facilities. Help-seeking behavior of the Vietnamese is influenced by Vietnamese concepts of mental illness and health, which are based on a mix of traditional and modern beliefs (Nguyen 2003; Phan and Silove 1999). Information is lacking on the perceptions about mental health and help-seeking behavior in Vietnamese communities. The aim of this study was therefore first to describe the perceptions of community members, family members of patients with mental illness and health workers in an urban setting in Vietnam about mental health and about appropriate help-seeking behavior, then to explore the relations between these perceptions.

Jorm et al. (1997, p.182) introduced the term 'mental health literacy' and define it as "knowledge and beliefs about mental disorders which aid their recognition, management and prevention". Mental health literacy includes the ability to recognize specific disorders; knowing how to seek mental health information; knowledge of risk factors and causes, of self-treatments, and of professional help available; and attitudes that promote recognition and appropriate help-seeking. The Health Belief Model (Rosenstock et al. 1988) attempts to predict health behavior by focusing on attitudes and beliefs. Relevant components of the Health Belief Model are 'perceived severity' and 'perceived barriers'. The factors addressed by these two models reflect important aspects of perceptions of mental health, perceptions of help-seeking behavior and the relation between them. Together, the aspects from the two models form a conceptual framework along which the methods and analyses were structured.

\section{Methods}

\section{Study Design}

This study used an explorative design.

\section{Study Area}

The study was carried out in Hue city, the capital of Thua Thien Hue province in central Vietnam, which has more than 300,000 inhabitants. Hue Central Hospital has a psychiatric ward serving nearly one million people in Thua Thien Hue province, and providing inpatient care. The Provincial Psychiatric Department provides outpatient care in the province and has a network to the community level. Primary health care doctors, who provide community based care in Community Health Centers (CHCs) in the 25 quarters and communes in Hue city, are also involved in this network.

From the 25 quarters and communes, four were randomly selected as the study areas, by picking them from a phonebook: Phu Binh, Phu Hau, Vinh Ninh and Truong An, with populations of, respectively 11,124, 10,415, 9,084 and 14,441 . The target population included adults 18 years and older from these four quarters.

\section{Study Methods}

\section{Questionnaire}

From each of the four quarters, 50 respondents were selected, which provided a total sample size of 200 adults. The selection of respondents was done randomly by selecting one adult from every 5th household on the registration lists in the health centers (which listed all households in a quarter). Demographic data of the respondents are presented in Table 1.

People's perceptions and attitudes towards mental health were investigated using a four-part, semi-structured questionnaire. The questionnaire included both open and closed questions. The first part collected demographic data about the respondents, including age, gender, marital status, occupation, education level, ethnicity and religion. The second part addressed awareness and knowledge of respondents about mental illness, its symptoms, causes and treatment options; these questions were based on the content of questionnaires used in previously published studies on mental illness (Kabir et al. 2004; Deribew and Tamirat 
Table 1 Demographic data of the 200 questionnaire respondents

\begin{tabular}{ll}
\hline Age $(\mathrm{M})$ & $46.0(S D=15.7)$ \\
Sex & Male $=50 \% /$ Female $=50 \%$ \\
Occupation & Sales $=21 \% /$ Civil servant $=15 \% /$ Housewife $=13.5 \% /$ Retired $=13.5 \% /$ \\
& Worker $=6 \% /$ Student $=6 \%$ \\
Education & Illiterate $=5 \% /$ Reading $\&$ writing $=4.5 \% /$ Primary school $=15.5 \% /$ \\
& Secondary school $=26.5 \% / \mathrm{High}$ school $=28.5 \% /$ University and over $=20 \%$ \\
Religion & Buddhist $=70 \% /$ Catholic $=4.5 \% /$ Not religious $=25.5 \%$ \\
\hline
\end{tabular}

2005). This part included four main questions, which were posed first as open questions, then as closed questions in which respondents could indicate on a dichotomous scale whether they did or did not recognize a certain illness, ${ }^{1}$ symptom, cause or treatment. The third part explored attitudes towards people with mental illness and perceived severity by using vignettes describing four cases, each representing one mental illness (major depression, alcohol dependency, generalized anxiety disorder and schizophrenia) and one representing a physical illness (diabetes). For each illness, attitudes were measured by the cumulative scores of five items each with a response on a 5-point Likert scale. Three items assessed the respondents' expectations of a patient's future and two items assessed social distance (the willingness to engage in relationships of varying intimacy with a person). The perceived severity of each illness was measured by one item using a 5-point Likert scale. Furthermore, respondents could indicate whether they thought the person depicted in the vignette had a mental illness and whether this person needed treatment. If the respondent indicated a need for treatment, an open question was posed about the appropriate treatment. The vignettes and items measuring attitudes were based on the "Attitudes to Mental Illness Questionnaire" (AMIQ) (Luty et al. 2006) but adapted to the local context. The fourth part of the questionnaire inquired about personal experiences with mental illness in eight open questions.

The questionnaire was developed with the help and advice of local mental health experts. It was constructed in English, translated into Vietnamese and checked for consistency of translation by a third person. A pilot study with 8 respondents was carried out before finalisation of the questionnaire. The data were collected by interview, which was done by a group of 12 master students of Hue Medical University who had been trained for one day on the questionnaire and on interview techniques. The respondents were asked for their informed consent before the interview. The collected data were translated into English, entered in Epi-Info $6.0^{\circledR}$ and converted for analysis in SPSS-13.

\footnotetext{
${ }^{1}$ Since epilepsy is part of the national mental health plan in Vietnam it was included in the closed questions.
}

In the presentation of the results, distinction is often made between the responses obtained using open and closed questions. This is important because in the open questions, which came first, the respondents had to come up with the information themselves, while in the closed questions, we presented possibilities and they could choose among them. When the results were similar in the two cases, the likelihood that the perception was strongly rooted is high, whereas responses that were only given when elicited by the closed questions might be less obvious or familiar to the respondents.

\section{Focus Group Discussions}

Eight focus group discussions (FGDs) were held, four with people unrelated to any patient with a mental health problem, and four with relatives of mental health patients. These participants were selected by convenience sampling through the health centers of the four quarters. Table 2 shows the number of participants of the eight FGDs and relating demographic data.

In the discussions with the four patient-unrelated groups, a first exercise addressed the identification of symptoms of mental illness. During the second exercise, the participants were asked to discuss a case story describing one of the following mental illnesses: major depression, generalized anxiety disorder or schizophrenia. The case stories were based on those used in a study by Deribew and Tamirat (2005) but adapted to the local context. In the four patientrelated FGD, the first exercise included a similar discussion about one of the same three case stories. The second exercise for these groups addressed the identification of perceived obstacles in the accessibility to mental health care.

The first FGD was considered a pilot session. However, because only minor changes were then made in the guidelines, the data were included in the final analysis. All FGD took place in the Community Health Centers of the four quarters and all were attended by one moderator and one observer. The moderator was a $\mathrm{PhD}$ student at Hue Medical University, who had been trained and carefully instructed in using the structured guidelines. At the start of each session, the participants were informed about the purpose of the discussion and were asked for their consent, also for the use of a tape recorder. The FGD results were 
Table 2 Number of FGD participants and demographic data

\begin{tabular}{|c|c|c|c|c|c|c|c|c|c|}
\hline & \multicolumn{5}{|c|}{ Patient unrelated } & \multicolumn{3}{|c|}{ Patient related } & \multirow[t]{2}{*}{ Total } \\
\hline & FGD 1 & FGD 2 & FGD3 & FGD4 & FGD5 & FGD6 & FGD7 & FGD8 & \\
\hline $\mathrm{N}(\mathrm{M} / \mathrm{F})^{*}$ & $10(7 / 3)$ & $9(2 / 7)$ & $10(1 / 9)$ & $8(2 / 6)$ & $10(2 / 8)$ & $7(5 / 2)$ & $10(0 / 10)$ & $12(4 / 8)$ & $76(23 / 53)$ \\
\hline Age (M) & 54.1 & 53.7 & 44.8 & 61,3 & 49.4 & 47.7 & 45.5 & 56.6 & 51.6 \\
\hline
\end{tabular}

$*(\mathrm{M}=$ male/F $=$ female $)$

analysed after manual coding by a "summarizing content analysis" method (Flick et al. 2004).

\section{Ethical Approval}

The study was approved by the Research Committee of the Hue Medical College for both its scientific planning and the ethical aspects related to the research. There are no known conflicts of interest and all authors certify responsibility for the manuscript.

\section{Results}

Attitudes and Beliefs

\section{Mental Illnesses}

Table 3 shows that more than half of the respondents could not identify a mental illness in response to the open questions in the questionnaire. Schizophrenia was overall the most frequently identified mental illness. Depression was the most identified illness in the closed questions, while it was seldom identified by the open questions and the vignettes. Anxiety was often recognized as a mental illness in the vignettes, but seldom in response to the open and closed questions. Other mental illnesses regularly recognized by the respondents were psychosis or nerve problems, stress, epilepsy and alcoholism. Participants in the focus group discussions often recognized correctly the case describing schizophrenia, while the case story presenting a case of depression was mostly associated with psychosis or nerve problems. The case story describing a person with anxiety disorder was usually referred to as a condition of 'thinking too much'.

\section{Symptoms}

Table 4 shows that overt abnormal behavior was, what most people identified as a symptom of mental illness. In the open questions, respondents often referred to strange or unusual behavior in general. The most commonly identified symptoms were related to abnormal talking and laughing followed by wandering. Other symptoms of mental illness often identified in both open and closed questions were aggression or violence and loss of memory or recognition. Imagining things was a symptom that only appeared in the closed questions. The participants of the focus group discussions also identified several clusters of symptoms. The symptom

Table 4 Perceived symptoms of mental illness

\begin{tabular}{|c|c|c|c|c|}
\hline \multirow[t]{2}{*}{ Rank } & \multicolumn{2}{|l|}{ Open questions } & \multicolumn{2}{|l|}{ Closed questions } \\
\hline & Response & $(\%)^{*}$ & Response & $(\%)^{*}$ \\
\hline 1 & Talking nonsense & 39.5 & $\begin{array}{l}\text { Talking/laughing } \\
\text { alone }\end{array}$ & 90.5 \\
\hline 2 & Wandering & 35.5 & Wandering & 89.9 \\
\hline 3 & Strange/unusual behavior & 25.5 & Loss of memory & 82.5 \\
\hline 4 & Aggression/violence & 18.5 & Imagining things & 70.4 \\
\hline 5 & $\begin{array}{l}\text { Loss of memory/ } \\
\text { recognition }\end{array}$ & 16.5 & Talkativeness & 49.0 \\
\hline 6 & Talking/laughing alone & 16.0 & Aggression & 43.2 \\
\hline
\end{tabular}

* Multiple responses recorded. Percentages represent proportions of respondents

Table 3 Mental illnesses identified by respondents

\begin{tabular}{|c|c|c|c|c|c|c|}
\hline \multirow[t]{2}{*}{ Rank } & \multicolumn{2}{|l|}{ Open questions } & \multicolumn{2}{|c|}{ Closed questions } & \multicolumn{2}{|l|}{ Vignettes } \\
\hline & Response & $(\%)^{*}$ & Response & $(\%)^{*}$ & Response & $(\%)^{*}$ \\
\hline 1 & Do not know & 32.0 & Depression & 63.0 & Schizophrenia & 85.5 \\
\hline 2 & Mad/insane & 31.0 & Schizophrenia & 55.5 & Anxiety & 44.5 \\
\hline 3 & Abnormal mental status & 18.0 & Stress & 51.5 & Alcoholism & 28.5 \\
\hline 4 & Schizophrenia & 14.5 & Epilepsy & 43.0 & Depression & 7.0 \\
\hline 5 & Psychosis/nerve problem & 10.5 & Anxiety & 33.0 & Diabetes & 1.0 \\
\hline
\end{tabular}

* Multiple responses were recorded; percentages represent proportions of respondents per response 
cluster 'unconscious behavior' was most often associated with strange behavior, talking or laughing alone, improper dressing and abnormal eating behavior, while the symptom cluster 'sad or unhappy' was mostly associated with abnormal facial expressions and avoiding contact or isolation.

\section{Causes}

Table 5 shows that when respondents were asked about the causes of mental illness, they usually mentioned stress or tension and studying or thinking too much. Other prevalent explanations were often related to emotional problems and included psychological or emotional shock, emotional distress and internal emotional problems. Respondents also came up with biological causes, naming genetic and congenital conditions and brain disturbance. The environment could also cause mental illness, according to the responses in both open and closed questions, in particular family and marital conflicts. The closed questions led to identification of accident or injury as causes but these did not appear in the open questions. During the focus group discussions about the case stories, the schizophrenia case was mostly associated with the causes genetics, work and love. The case story describing a case of depression was usually associated with family problems, while financial problems were considered as the most likely cause in the anxiety case story.

\section{Treatment}

Table 6 reveals that in response to both open and closed questions, the majority of the respondents preferred medical treatment options, such as psychiatric hospital or psychiatrist, hospital or doctor and drugs. Besides medical care, many participants also expected results from the support of family and friends and care at home. Only a minority of respondents considered treatment by traditional healers as a possibility and only in the closed questions. For the vignettes describing cases of depression, anxiety and schizophrenia, medical treatment was the most common recommendation, followed by family care. For the alcoholism vignette, giving up drinking was the most common response, followed by medical treatment. When the focus groups discussed the case stories, support from family and friends was considered the most appropriate way to deal with all kinds of mental illness, although often in combination with medical treatment options.

\section{Attitudes}

Respondents showed the most negative attitude towards the person depicted in the alcoholism vignette $(\mathrm{M}=$ 17.66) followed by the schizophrenia vignette $(\mathrm{M}=$ 17.09). The most positive attitude was expressed towards the person with a physical illness $(M=10.49)$. People with lower education levels had significantly more positive attitudes towards mental illness in general than did those with higher education levels $(\mathrm{t}=1.978, d f=$ $178.760, P=0.049)$. Those who named their religion as Buddhism also had more positive attitudes towards mental illness than non-Buddhists $(\mathrm{t}=3.410, d f=130.269$, $P=0.001)$.
Table 5 Perceived causes of mental illness

* Multiple responses recorded. Percentages represent proportions of respondents

Table 6 Preferred treatment for mental illness

* Multiple responses recorded. Percentages represent proportions of respondents

\begin{tabular}{llllll}
\hline Rank & Open questions & & Closed questions & \\
& Response & $(\%)^{*}$ & & Response & $(\%)^{*}$ \\
\hline 1 & Stress/tension & 31.0 & & Accident/injury & 82.7 \\
2 & Thinking/studying too much & 23.0 & & Thinking/studying too much & 81.9 \\
3 & Psychological/sentimental shock & 22.0 & & Emotional distress & 80.4 \\
4 & Genetic/congenital & 18.5 & & Brain disturbance & 80.3 \\
5 & Family events/conflict & 18.5 & & Conflict in marriage or family & 59.6 \\
6 & Internal emotional problems & 17.0 & & Worrying too much & 56.5 \\
\hline
\end{tabular}

\begin{tabular}{llllll}
\hline Rank & Open questions & & Closed questions & \\
\cline { 2 - 3 } \cline { 5 - 6 } & Response & $(\%)^{*}$ & & Response & $(\%)^{*}$ \\
\hline 1 & Psychiatric hospital/psychiatrist & 50.5 & & General hospital/CHC & 98.0 \\
2 & Hospital/doctor & 47.0 & & Mental health ward & 97.0 \\
3 & Drugs & 28.5 & & Drugs & 95.0 \\
4 & Support family/friends & 20.0 & & Family & 64.5 \\
5 & Treatment at home & 17.5 & & Local traditional healer & 34.5 \\
\hline
\end{tabular}




\section{Perceived Severity}

Of the four vignettes describing mental illnesses, the respondents considered the schizophrenia vignette to be the most severe $(\mathrm{M}=3.33)$ followed by the alcoholism vignette $(\mathrm{M}=2.55)$, while anxiety $(\mathrm{M}=2.25)$ and depression $(M=2.24)$ were considered the least severe. Respondents with lower education levels perceived schizophrenia and anxiety disorder as significantly more severe than did those with higher education levels (respectively $\mathrm{t}=2.456, d f=178.729, P=0.015$ and $\mathrm{t}=2.564, d f=194, P=0.011)$. Looking at the symptom clusters identified during the focus groups, the symptom cluster 'unconscious behavior' was thought to be most severe followed by the cluster 'sad or unhappy'. Other symptom clusters that respondents rated among the most severe were 'aggression or violence', 'wandering' and 'agitation or bad temper'. Only in case of the four most severe symptoms, people suggested that the patient should seek care in a psychiatric hospital or mental institution, while support from family or friends was thought to be appropriate for all symptom clusters.

\section{Perceived Barriers}

During the FGDs, patient relatives identified several obstacles in the delivery of mental health care to patients. The most commonly identified obstacles were a lack of drugs (usually identified as vitamins), financial problems and the burden of taking care of the patient. Drugs specific for the illness were sometimes lacking or supplied with delay. The lack of financial support and poverty were also important obstacles. Family members have to give up their jobs to take care of the patient and lose income, while the family has extra expenses for drugs and other materials for the patient. The burden of care by a family member was an important obstacle, specifically the emotional burden, the difficulties in patient management and potentially, aggression from the patient. The following comment reflects the emotional part of the burden: "Sometimes I get so tired and angry that I secretly hope the patient dies, but I do not really want this and I will always worry about him". Discussing the topic of aggression from patients a mother said about her schizophrenic son: "My son controls me with aggression, he threatens me and sometimes he beats me when I cannot meet his demands".

\section{Discussion}

This study looked at perceptions of mental health and helpseeking behavior in Vietnam. The results identify several aspects, which have an important influence on these concepts. Below, the relevance of the identified lack of knowledge, attitudes and beliefs, help-seeking behavior and the burden of giving care by families and the relationship between these concepts are discussed.

\section{Lack of Knowledge}

The results reveal a general lack of knowledge on mental health among this population of relatively well-educated urban residents in Central Vietnam. Most people could not spontaneously name any mental illness and used the words mad and insane to describe this condition. Nguyen (2003) indicates that this terminology is common in Vietnam in the context of mental illness. The most common actual mental disorder identified by our respondents was schizophrenia. Part of the respondents recognized epilepsy as a mental illness although it is a neurological condition. People might not distinguish between these conditions because of an overlap in symptoms and attributed causes. This might also reflect the scope of the national mental health program, which for a long time only focused on schizophrenia and epilepsy as mental illnesses. Depression was identified as a mental illness using some methods but not for all, while anxiety disorder was hardly recognized as a mental illness. In an Australian survey (Jorm et al. 1997) respondents more often recognized the presence of a mental disorder in a vignette describing a case of schizophrenia than in a depression vignette. The findings from our study were comparable, in that the respondents ranked schizophrenia as the most severe condition, while depression and anxiety were considered the least severe. Deribew and Tamirat (2005) reported similar findings from a study in Ethiopia and found that people only recognized severe psychotic conditions as mental disorders. Similarly, we found that behaviors such as talking nonsense, wandering, strange behavior and aggression or violence were the most frequently mentioned symptoms of mental illness in the questionnaire. Results from the focus group discussions showed that the symptom clusters of 'unconscious or strange behavior', 'aggression' and 'wandering' were ranked as the most severe problems. These findings are in agreement with those from studies carried out in Africa (Kabir et al. 2004; Deribew and Tamirat 2005), suggesting that overt psychotic behavior that attracts public attention and is socially disruptive is associated with mental illness, in any society. These results suggest that perceptions of the severity of mental illnesses are strongly related to the recognition of those illnesses and related symptoms, and that both are strongly influenced by a lack of knowledge and awareness. Furthermore, Jorm (2000) stated that many members of the public in developing as well as developed countries cannot correctly recognize mental disorders and do not understand the meanings of psychiatric terms. This 
causes problems in communication with health practitioners who often miss patients with mental disorders.

\section{Attitudes and Beliefs}

Vietnamese attitudes and beliefs concerning mental health are influenced by a lack of knowledge as well as a mix of traditional and modern views. Respondents often identified 'stress' and 'nerve problems' as mental illnesses. When respondents were asked about the causes of mental illness, those most frequently mentioned were 'stress or tension' and 'excessive studying or thinking'. Nguyen (2003) documented similar perceived causes of mental illnesses among Vietnamese people in Ho Chi Minh City and mentions that it is a common belief in Vietnam that people can fall mentally ill from studying or thinking too much. These findings point at culture specific perceptions of mental health in relation to stress and mental overload. There were incongruent findings for the recognition of depression and anxiety in this study. Although the lack of knowledge is likely to play a role in this, culture specific explanations can also be found in the literature. Wagner et al. (2006) found that Vietnamese people did not differentiate clearly between the terms 'stress', 'depression' and 'anxiety', which are used as different words for a single psychological construct. It is notable that participants in our study sometimes gave traditional explanations for mental illnesses, but much less frequently than modern explanations. A possible explanation for this finding is that respondents answered in a socially desirable way in which modern views of mental health would be more socially desirable than traditional views. However, it is more likely that modern views on mental health were in fact more dominant in our study population. The study was done with a relatively well-educated urban population, which is more likely to have a modern view and to prefer natural causes over supernatural causes than might less educated and more rural populations (Nguyen 2003).

Attitudes towards the different mental illness vignettes in the questionnaire were most negative for the alcoholism vignette, followed by the schizophrenia vignette. These results suggest that people have the most negative attitudes towards mental illnesses associated with socially disruptive behavior, which is in line with findings from Deribew and Tamirat (2005). The results of an Australian survey among the general public and professionals showed that both groups rated outcomes as poorer and discrimination as more likely for schizophrenia than for depression (Jorm et al. 1999). The finding that people with low education levels had a more positive attitude towards mental illnesses than did respondents with higher education levels is in contradiction with many studies suggesting that positive attitudes towards mental patients are related to higher education levels (Trute et al. 1989; Kabir et al. 2004; Deribew and Tamirat 2005). However, there is also literature providing an explanation for our finding. Lauber et al. (2004) found that increased understanding of mental illnesses leads to greater social distance, which was one of the indicators of attitude in our study. Thus, more knowledge of mental illnesses seems to decrease the willingness to engage in social relationships with mentally ill people. More research is needed to further investigate this finding and possible explanations.

\section{Help-seeking Behavior}

Modern medical treatment was preferred by a majority of the study population. Similar preferences were found in other studies on perceptions of mental health (Deribew and Tamirat 2005; Kabir et al. 2004). A considerable number of people also recommended family support and care at home. It is plausible that both treatment approaches are often used together and differences in preference might occur according to differences in the perceived severity of a mental disorder. The results show that only for the four most severe symptom clusters did the respondents suggest seeking care in a psychiatric hospital or mental institution, while support from family and friends was mentioned for all symptom clusters. Apparently, people prefer to take care of persons with a mental illness in the family, but will bring the patient to a psychiatric hospital if the condition is very severe, which is consistent with the findings by Nguyen (2003) and Wagner et al. (2006). The fact that people seldom mentioned other treatment options besides family care for mental illnesses other than schizophrenia indicates that in many cases the Vietnamese population is unlikely to use mental health care services. The results may reflect a perception at least that such services are either not available or not accessible, or not acceptable, especially for the treatment of less severe mental illnesses. Jorm (2000) reported that in Australia and the UK, when the members of the public were asked to rate the likely helpfulness of a range of interventions for mental disorders, self-help interventions, including seeking help from family and friends, were on top of the list. The help-seeking behavior of the Vietnamese is likely to be influenced by the lack of knowledge about and the attitudes and beliefs towards mental health care services. James et al. (2002) found a strong relationship between health seeking behaviors, perceptions of the local population and the use of mental health care services in India and Pakistan. Social stigma towards mental illnesses could also play a role in reducing the number of people willing to seek treatment for mental health problems (Corrigan 2004). In the UK, a majority of the public reported that they would be embarrassed to consult a general practitioner for depression (Priest et al. 1996). 
Family Burden

Patient relatives identified the heavy burden of giving care as an important barrier to providing care for a relative with mental health problems. Caregivers experienced financial burdens, emotional burdens, disruptions to family routines and difficulties in dealing with aggression by the patient. Wong et al. (2004) confirmed the strong positive relationship between family burdens and distress among caregivers and suggested that culturally specific health beliefs influence the way caregivers experience the family burden of care and that this is related to help-seeking behaviour. Because family members only help patients to seek medical treatment in severe cases and usually take care of patients at home until the situation becomes intolerable, they find themselves confronted with a huge burden on the family. With a lack of financial resources and limited knowledge of mental illnesses and mental health care services, caregivers find it hard to deal appropriately with their situation.

\section{Conclusions}

This study gives unique insights into the perceptions of mental health and help-seeking behavior among an urban population in Central Vietnam. The results demonstrate a need for educational and awareness programs about the nature and symptoms of mental illnesses and in particular about neglected common illnesses like mood and anxiety disorders. Programs should address the different treatment options and people should be encouraged to seek help in an early stage of illness. In developing such programs culturespecific notions of mental illness should be taken into account. The importance of the family should de acknowledged and efforts should be made to understand the needs of families, in order to provide them with support and skill training and to help them organize family groups and associations. More research is needed on prevalence rates of mental disorders, the availability and accessibility of mental health care services and stigma in Vietnam, especially in rural areas. For programs and research on mental health, it is important to have support from national and regional authorities. The current trend in which we see a broadening of policies on mental health could create opportunities for development of successful mental health programs.

Open Access This article is distributed under the terms of the Creative Commons Attribution Noncommercial License which permits any noncommercial use, distribution, and reproduction in any medium, provided the original author(s) and source are credited.

\section{References}

Corrigan, P. (2004). How stigma interferes with mental health care. American Psychologist, 59(7), 612-625.

Deribew, A., \& Tamirat, Y. S. (2005). How are mental health problems perceived by a community in Agaro town. Ethiopian Journal of Health Development, 19(2), 153-159.

Fisher, J. R., Morrow, M. M., Nhu Ngoc, N. T., \& Hoang Anh, L. (2004). Prevalence, nature, severity and correlates of postpartum depressive symptoms in Vietnam. International Journal of Obstetrics and Gynaecology, 111, 1353-1360.

Flick, U., Von Kardoff, E., \& Steinke, I. (2004). A Companion to Qualitative Research. London: Sage.

Giang, K. B. (2006). Assessing health problems: Self reported illness, mental distress and alcohol problems in a rural district in Vietnam. Dissertations from Karolinska Intitutet 2006.

Giel, R., \& Harding, T. W. (1976). Psychiatric priorities in developing countries. The British Journal of Psychiatry, 128(6), 513-522.

Harpham, T., \& Tuan, T. (2006). From research evidence to policy: mental health care in Vietnam. Bulletin of the World Health Organization, 84(8), 664-668.

Hwu, H.-G., Yeh, E.-K., \& Chang, L.-Y. (2007). Prevalence of psychiatric disorders in Taiwan defined by the Chinese Diagnostic Interview Schedule. Acta Psychiatrica Scandinavica, 79(2), 136-147.

Jacob, K. S., Sharan, P., Mirza, I., Garrido-Cumbrera, M., Seedat, S., Mari, J. J., et al. (2007). Mental health systems in countries: Where are we now? Lancet, 370, 1061-1077.

James, S., Chisholm, D., Srinavasa Murthy, R., Kishore Kumar, K., Sekar, K., Saeed, K., et al. (2002). Demand for, access to and use of community mental health care: Lessons from a demonstration project in India and Pakistan. International Journal of Social Psychiatry, 48(3), 163-176.

Jorm, A. F. (2000). Mental health literacy. Public knowledge and beliefs about mental disorders. British Journal of Psychiatry, 177, 396-401.

Jorm, A. F., Korten, A. E., Jacomb, P. A., Christensen, H., \& Henderson, S. (1999). Attitudes towards people with a mental disorder: a survey of the Australian public and health professionals. Australian and New Zealand Journal of Psychiatry, 33(1), 77-83.

Jorm, A. F., Korten, A. E., Jacomb, P. A., Christensen, H., Rodgers, B., \& Pollit, P. (1997). "Mental health literacy": A survey of the public's ability to recognize mental disorders and their beliefs about the effectiveness of treatment. Medical Journal of Australia, 166, 182-186.

Kabir, M., Iliyasu, Z., Abubakar, I.S., Aliyu, M.H. (2004). Perception and beliefs about mental illness among adults in Karfi village, northern Nigeria. BMC International Health and Human Rights, 4(3). Published online 2004 August 20.

Kessler, R. C., McGonagle, K. A., Zhao, S., Nelson, C. B., Hughes, M., Eshleman, S., et al. (1994). Lifetime and 12-month prevalence of DSM-III-R psychiatric disorders in the United States. Results from the national comorbidity survey. Archives of General Psychiatry, 51(1), 8-19.

Lauber, C., Nordt, C., Falcato, L., \& Rössler, W. (2004). Factors influencing social distance toward people with mental illness. Community Mental Health Journal, 40(3), 265-274.

Luty, J., Fekadu, D., Umoh, O., \& Gallagher, J. (2006). Validation of a short instrument to measure stigmatised attitudes towards mental illness papers. Psychiatric Bulletin, 30, 257-260.

Mathers, C. D., \& Loncar, D. (2006). Projections of global mortality, burden of disease from 2002 to 2030. PLoS Medicine, 3(11), 211-230. 
Mbuba, C. K., \& Newton, C. R. (2009). Packages of care for epilepsy in low- middle-income countries. PLoS Medicine, 6(10), 1-7.

Nguyen, A. (2003). Cultural and social attitudes towards mental illness in Ho Chi Minh City, Vietnam. Stanford Undergraduate Research Journal, 2.

Patel, V., Saraceno, B., \& Kleinman, A. (2006). Beyond Evidence: The moral case for international mental health. American Journal of Psychiatry, 163(8), 1312-1315.

Phan, T., \& Silove, D. (1999). An overview of indigenous descriptions of mental phenomena and the range of traditional healing practices amongst the Vietnamese. Transcultural psychiatry, 36(1), 79-94.

Priest, R. G., Vize, C., \& Roberts, A. (1996). Lay people's attitudes to treatment of depression: results of opinion poll for Defeat Depression Campaign just before its launch. British Medical Journal, 313, 858-859.

Rosenstock, I. M., Strecher, V. J., \& Becker, M. H. (1988). Social learning theory and the health belief model. Health Education \& Behavior, 15(2), 175-183.
Trute, B., Tefft, B., \& Segall, A. (1989). Social rejection of the mentally ill: a replication study of public attitude. Social Psychiatry and Psychiatric Epidemiology, 24, 69-76.

Wagner, R., Manicavasagar, V., Silove, D., Marnane, C., \& Tran, V. T. (2006). Characteristics of Vietnamese patients attending an anxiety clinic in Australia and perceptions of the wider Vietnamese community about anxiety. Transcultural Psychiatry, 43(2), 259-274

WHO World Mental Health Consortium. (2004). Prevalence, severity, and unmet need for treatment of mental disorders in the World Health Organization World Mental Health Surveys. The Journal of the American Medical Association, 291(21), 2581-2590.

Wong, D. F. K., Tsui, H. K. P., Pearson, V., Chen, E. Y. H., \& Chiu, S. N. (2004). Family Burdens, Chinese Health Beliefs, and the Mental Health of Chinese Caregivers in Hong Kong. Transcultural Psychyiatry, 41(4), 497-513.

World Health Organization. (2001). The World Health Report 2001Mental health: new understanding new hope. Geneva: World Health Organization. 